\title{
ANALISIS AGROINDUSTRI KRIPIK UBI KAYU DI KELURAHAN KULIM KECAMATAN TENAYAN RAYA KOTA PEKANBARU
}

\author{
Niken Nurwati, Rini Nizar, Amalia \\ Fakultas Pertanian Universitas Lancang Kuning
}

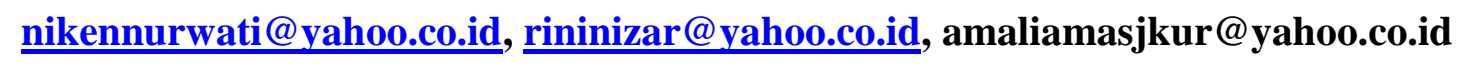

\begin{abstract}
The agricultural sector is the main pillar of economic development in Indonesia because Indonesia almost all economic activities centered on the sector. Processing of agricultural or agro-industry is the agricultural product processing business for the purpose of increasing the value of the product. Pekanbaru city produces one of the agricultural products that manioc. The highest production of cassava in Sub Tenayan Raya in Pekanbaru, namely 11210 tonnes (Pekanbaru in number 2015).

In connection with this condition, this study aims to analyze costs and revenues, Break Even Point (BEP), profit planning as well as the added value generated by the agroindustry critic's capable of cassava in Kulim Tenayan Raya Pekanbaru.

It can be concluded:

1. The cost of agro-industrial production processes cassava chips "SUGENG

SNACK" In December 2016 flavors Balado is Rp. 40,822,557.40, original flavors Rp. 40,822,557.40 and chilli chips (Sanjai) Rp. 22,777,250.00. Net revenue cassava chips flavors Balado is Rp. 12,681,442.60, or Rp. 5,214 / Kg; Rp original flavors. $11,565,426.00$ or USD. 6763 / Kg; and crispy chilli (Sanjai) Rp. 5,613,570.00. or Rp.6577,-/Kg

2. Value BEP (Q) agroindustrial cassava chips "SUGENG SNACK" In December 2016 flavors Balado is $145.88 \mathrm{~kg}, 85.26 \mathrm{Kg}$ variants of the original flavor and crispy chilli (Sanjai) 48,45Kg. Total sales to achieve profit Rp.20.000.000, - for each variant flavors, flavors $\mathrm{Kg}$ Balado is $3751.34,2894.91 \mathrm{Kg}$ variants of the original flavor, and crispy chilli (Sanjai) $2922.03 \mathrm{Kg}$.

3. Value-added agro-industry cassava chips "SUGENG SNACK" In December 2016, flavors Balado is the output value of Rp. 8360, - provide added value for Rp.5.757, - or by $68.86 \%$, flavors original output value of Rp. 8360 , - provide added value amounting to Rp. 5627, - or by $67.3 \%$., And crispy chilli (Sanjai) output value amounted to Rp.12.768, - provide added value amounting to Rp. 9675 , - or a total of $75.776 \%$.
\end{abstract}

Keywords: Agro-industry, Revenue, Break Even Point, Profit Target, ValueAdded 


\section{PENDAHULUAN}

Sektor pertanian merupakan pilar utama pembangunan perekonomian Indonesia karena hampir seluruh kegiatan perekonomian Indonesia berpusat pada sektor tersebut. Salah satu upaya untuk meningkat kesejahteraan petani adalah dengan melakukan pengolahan hasil pertanian. Pengolahan hasil pertanian atau agroindustri merupakan usaha pengolahan hasil pertanian untuk tujuan peningkatan nilai produk. Kelurahan Kulim Kecamatan tenayan raya merupakan sentra ubi kayu yaitu 11.210 ton (Pekanbaru dalam angka 2015).

Penelitian ini bertujuan untuk melakukan analisis kelayakan usaha, Break Even Poin (BEP), perencanaan laba serta nilai tambah yang mampu dihasilkan oleh agoindustri kripik ubi kayu. Diharapkan hasil penelitian ini dapat memberikan masukan untuk pengembangan agoindustri kripik ubi kayu di Kecamatan Tenayan Raya kota Pekanbaru.

Analisis usaha merupakan suatu hal yang perlu diterapkan oleh suatu usaha untuk melihat apakah usaha yang dijalankan tersebut sudah mampu memberikan keuntungan yang memadai bagi pengusaha. Dengan dilakukan analisis usaha diharapkan dapat mengidentifikasi komponen biaya yang mungkin masih dapat dihemat, berapa unit produk yang minimal harus dihasilkan agar usaha tidak rugi, serta berapa unit produk harus terjual agar mencapai keuntungan tertentu, dan berapa nilai tambah yang diperoleh.

\section{METODE PENELITIAN}

Metode yang dipergunakan dalam penelitian ini adalah metode survey. Penelitian dilaksanakan di Kelurahan Kulim Kecamatan Tenayan Raya Kota Pekanbaru. Pemilihan lokasi penelitian ini atas dasar pertimbangan bahwa pada Kelurahan ini merupakan sentra produksi keripik ubi kayu. Waktu penelitian selama kurang lebih dua bulan, yaitu dari bulan Oktober 2016 sampai dengan Desember 2016.

Penarikan sampel dilakukan secara purposive terhadap satu usaha pengolahan kripik ubi kayu paling besar skala usahanya.

Data yang dikumpulkan dalam penelitian ini meliputi data primer dan data sekunder. Data primer diperoleh dari responden dengan menggunakan daftar pertanyaan (Questioner) dan pengamatan langsung di lapangan.

Untuk menghitung biaya penyusutan alat digunakan rumus menurut Hernanto ( 1989 ),

$$
D=\frac{N b-N s}{N}
$$

Dimana :

$\mathrm{D} \quad=$ Depretion $/$ penyusutan $(\mathrm{Rp}$ proses produksi )

$\mathrm{Nb}=$ Nilai baru ( $\mathrm{Rp} /$ unit $)$

Ns = Nilai sisa ( $\mathrm{Rp} /$ unit $)$

$\mathrm{N}=$ Umur ekonomis ( tahun )

Untuk meghitung penerimaan bersih agroindustri nenas digunakan rumus menurut Sukartawati (1987) sebagai berikut : 


$$
\begin{aligned}
& \Pi=\mathrm{TR}-\mathrm{TC} \\
& \Pi=\mathrm{y} \cdot \mathrm{PY}-\mathrm{X} . \mathrm{Px}
\end{aligned}
$$

Dimana :

$\Pi$

$$
\text { = Pendapatan bersih usaha }
$$
agroindustri nenas ( $\mathrm{Rp} /$ proses produksi)

$\mathrm{Y} \quad=$ Jumlah produksi nenas $(\mathrm{Kg} /$ Proses produksi )

Py = Harga produksi nenas $(\mathrm{Rp} / \mathrm{Kg})$

$\mathrm{X}=$ Faktor produksi yang digunakan ( $\mathrm{Kg} /$ proses produksi )

$\mathrm{Px}=$ Harga Faktor produksi yang digunakan ( $\mathrm{Rp} / \mathrm{Kg}$ )
Untuk menghitung BEP digunakan rumus menurut Yacob, 2009 :158.

a

$$
\begin{aligned}
& \operatorname{BEP}_{(\mathrm{Q})}=\frac{}{(\mathrm{p}-\mathrm{b})} \\
& \operatorname{BEP}_{(\mathrm{Rp})}=\frac{\mathrm{a}}{(1-\mathrm{b} / \mathrm{p})}
\end{aligned}
$$

Dimana :

$$
\begin{array}{ll}
\mathrm{a} & =\text { Fixed Cost } \\
\mathrm{b} & =\text { Biaya variabel per unit } \\
\mathrm{p} & =\text { Harga per unit } \\
\mathrm{q} & =\text { Jumlah produksi }
\end{array}
$$

Untuk melakukan analisis volume-laba digunakan rumus menurut Downey W. David dan Erickson Steven P (1992) sbb:

Tambahan penjualan $=\frac{\text { Target laba }}{\text { KTO }}=\frac{\text { Target laba }}{\text { HU - BV }}$

Dimana :

KTO $=$ Kontribusi terhadap

overhead

$\mathrm{HU}=$ Harga jual produk

$\mathrm{BV}=$ Biaya variable/ unit produk

Untuk melakukan analisis nilai tambah

metode Hayami digunakan kerangka

analisis nilai tambah sebagai berikut: 
Tebel 1. Tabel Perhitungan Nilai Tambah

\begin{tabular}{|c|c|c|}
\hline No & Variabel & Nilai \\
\hline & Output, Input dan Harga & \\
\hline 1 & Output (kg/bulan) & $\mathrm{a}$ \\
\hline 2 & Bahan Baku (kg/bulan) & $\mathrm{B}$ \\
\hline 3 & Tenaga kerja (HOK/bulan) & $\mathrm{c}$ \\
\hline 4 & Faktor Konversi (1/2) & $\mathrm{d}=\mathrm{a} / \mathrm{b}$ \\
\hline 5 & Koefisien tenaga kerja (3/2) & $\mathrm{e}=\mathrm{c} / \mathrm{b}$ \\
\hline 6 & Harga output $(\mathrm{Rp} / \mathrm{kg})$ & f \\
\hline \multirow[t]{2}{*}{7} & Upah rata-rata tenaga kerja $(\mathrm{Rp} / \mathrm{HOK})$ & $\mathrm{g}$ \\
\hline & $\begin{array}{l}\text { Pendapatan dan Keuntungan (Rp/kg bahan } \\
\text { baku) }\end{array}$ & \\
\hline 8 & Harga bahan baku & $\mathrm{h}$ \\
\hline 9 & Sumbangan input lain & i \\
\hline 10 & Nilai output $(4 \times 6)$ & $\mathrm{J}=\mathrm{d} \times \mathrm{f}$ \\
\hline $11 \mathrm{a}$ & Nilai tambah (10-9-8) & $K=j-h-i$ \\
\hline $\mathrm{b}$ & Rasio nilai tambah $(11 \mathrm{a} / 10) \times 100 \%)$ & $1 \%=(\mathrm{k} / \mathrm{j}) \times 100 \%$ \\
\hline $12 \mathrm{a}$ & Imbalan tenaga kerja $(5 \times 7)$ & $\mathrm{m}=\mathrm{e} \times \mathrm{g}$ \\
\hline $\mathrm{b}$ & Bagian tenaga kerja (12a/11a) x 100\%) & $\begin{array}{l}\mathrm{n} \%=(\mathrm{m} / \mathrm{k}) \mathrm{x} \\
100 \%\end{array}$ \\
\hline $13 \mathrm{a}$ & Keuntungan $(11 \mathrm{a}-12 \mathrm{a})$ & $\mathrm{o}=\mathrm{k}-\mathrm{m}$ \\
\hline \multirow[t]{2}{*}{$\mathrm{b}$} & Tingkat keuntungan (13a/11a) x 100\% & $\begin{array}{l}\mathrm{p} \%=(\mathrm{o} / \mathrm{k}) \mathrm{x} \\
100 \%\end{array}$ \\
\hline & Balas Jasa Faktor Produksi & \\
\hline 14 & Marjin $(10-8)$ & $q=j-h$ \\
\hline $\mathrm{a}$ & Pendapatan tenaga kerja & $\begin{array}{l}\mathrm{r} \%=(\mathrm{m} / \mathrm{q}) \times \\
100 \%\end{array}$ \\
\hline $\mathrm{b}$ & Sumbangan input lain & $\mathrm{s} \%=(\mathrm{i} / \mathrm{q}) \times 100 \%$ \\
\hline $\mathrm{c}$ & Keuntungan perusahaan & $\mathrm{t} \%=(\mathrm{o} / \mathrm{q}) \times 100 \%$ \\
\hline
\end{tabular}

Sumber: Hayami,et al (1987)

\section{HASIL PENELITIAN DAN PEMBAHASAN}

\section{Keadaan Umum Daerah Penelitian}

Kelurahan Kulim adalah salah satu kelurahan di Kecamatan Tenayan Raya. Kelurahan Kulim terdiri dari 19 RW dan 71 Rt. Keadaan suhu di Kelurahan Kulim adalah 22-32 ${ }^{\circ} \mathrm{C}$, dengan topografi dari dataran sampai bergelombang sebesar $40 \%$ dan dari bergelombang sampai berbukitbukit sebesar $60 \%$. Ketinggian dari permukaan laut 0-6 $\mathrm{m}$ dpl.
Keadaan tingkat pendidikan penduduk di Kelurahan Kulim adalah sebagai berikut: 5.127 jiwa belum atau tidak sekolah, 6.781 tidak atau belum tamat SD, 3.815 jiwa tamat SD, 4.538 jiwa tamat SLTP, 4.907 tamat SLTA, 371 jiwa tamat D II, 450 jiwa tamat D III, 60 jiwa tamat Perguruan Tinggi atau D IV. (Tenayan Raya dalam Angka, 2014)

Profil Usaha Keripik Ubi Kayu Pak Sugeng

Usaha Keripik Ubi milik Bapak Sugeng terletak di Jl.Lintas Timur KM 17,5 Kulim - Pekanbaru, usaha ini 
dikelola pertama kali dimulai tahun 2009 dan sudah berjalan sampai sekarang. Produk yang dihasilkan sudah di kemas dengan baik dan diberi merk "SUGENG SNACK" dan diberi logo dari LPPOM , halal dari MUI, izin DIKES P-IRT No.206147101277, serta tanggal kadaluarsa. 


\section{Biaya Proses produksi Kripik Ubi Kayu}

Tabel 2. Total Biaya Agroindustri kripi ubi Kayu "SUGENG SNACK"Berdasarkan Varian Rasa Dalam Bulan Desember Tahun 2016

\begin{tabular}{|c|c|c|c|c|c|c|c|c|c|c|c|c|c|}
\hline \multirow[b]{2}{*}{ No } & \multirow[b]{2}{*}{ Uraian } & \multicolumn{4}{|c|}{ Kripik Balado } & \multicolumn{4}{|c|}{ Kripik Oroginal } & \multicolumn{4}{|c|}{ Kripik Rasa cabe (Spt Sanjai) } \\
\hline & & $\mathrm{Jml}$ & $\begin{array}{l}\text { Harga/unit } \\
\text { (Rp) }\end{array}$ & Biaya (Rp) & $\begin{array}{l}\text { Prosentase } \\
(\%)\end{array}$ & $\mathrm{Jml}$ & $\begin{array}{l}\text { Harga/unit } \\
\text { (Rp) }\end{array}$ & Biaya (Rp) & $\begin{array}{l}\text { Prosentase } \\
(\%)\end{array}$ & $\mathrm{Jml}$ & $\begin{array}{l}\text { Harga/un } \\
\text { it (Rp) }\end{array}$ & Biaya (Rp) & $\begin{array}{c}\text { Prosentase } \\
(\%)\end{array}$ \\
\hline \multirow{20}{*}{$2^{1}$} & Biaya Tetap & 2.432 & 351 & 853.335 & 2,06 & 1.710 & 351 & 600.001 & 2,30 & 855 & 351 & 300.001 & 1,33 \\
\hline & Biaya Tidak Tetap & & & & - & & & & - & & & & - \\
\hline & a. Bahan Baku Ubi (Kg) & 6.400 & 1.600 & 10.240 .000 & 24,73 & 4.500 & 1.600 & 7.200 .000 & 27,56 & 2.250 & 1.600 & 3.600 .000 & 15,97 \\
\hline & b. Bahan Penunjang : & & & & - & & & - & - & & & & - \\
\hline & 1).Minyak goreng (1) & 427 & 15.000 & 6.400 .000 & 15,46 & 300 & 15.000 & 4.500 .000 & 17,22 & 150 & 15.000 & 2.250 .000 & 9,98 \\
\hline & 2).Penyedap (bks) & & & - & - & 855 & 500 & 427.500 & 1,64 & & & & - \\
\hline & 3).Bumbu Kripik Cabe & & & & - & & & - & - & & & & - \\
\hline & a. Cabe $(\mathrm{Kg})$ & & & - & - & & & & - & 115 & 50.000 & 5.740 .000 & 25,46 \\
\hline & b. Bawang putih $(\mathrm{Kg})$ & & & - & - & & & - & - & 30 & 25.000 & 750.000 & 3,33 \\
\hline & c. Gula $(\mathrm{Kg})$ & & & - & - & & & - & - & 50 & 15.000 & 750.000 & 3,33 \\
\hline & d. Penyedap (bks) & & & - & - & & & - & - & 90 & 1.000 & 90.000 & 0,40 \\
\hline & e. Minyak goreng (1) & & & - & - & & & - & - & 100 & 15.000 & 1.500 .000 & 6,65 \\
\hline & 4).Balado (bks) & 973 & 5.000 & 4.864 .000 & 11,75 & & & - & - & - & - & - & - \\
\hline & 5). Kayu bakar (truk) & 2 & 500.000 & 1.015 .992 & 2,45 & 1 & 500.000 & 714.165 & 2,73 & 1 & 500.000 & 357.229 & 1,58 \\
\hline & 6). Plastik & 79 & 36.000 & 2.837 .333 & 6,85 & 55 & 36.000 & 1.995 .000 & 7,64 & 28 & 36.000 & 997.500 & 4,43 \\
\hline & 7).Listrik & & & 180.000 & 0,43 & & & 135.000 & 0,52 & & & 75.000 & 0,33 \\
\hline & c. Tenaga Kerja & 124 & & 8.128 .000 & 19,63 & 90 & & 5.715 .000 & 21,87 & 55 & & 3.712 .500 & 16,47 \\
\hline & d. Pemasaran & 2.432 & 2.830 & 6.883 .772 & 16,63 & 1.710 & 2.830 & 4.840 .152 & 18,53 & 855 & 2.830 & 2.420 .076 & 10,74 \\
\hline & Jumlah 2 & & & 40.549 .097 & 97,94 & & & 25.526 .817 & 97,70 & & & 22.242 .305 & 98,67 \\
\hline & Total & & & 41.402 .433 & 100,00 & & & 26.126 .819 & 100,00 & & & 22.542 .305 & 100,00 \\
\hline
\end{tabular}

Sumber: Olahan Data Primer 2016

Jurnal Ilmiah Pertanian Vol. 14 No.1, Agustus 2017 


\section{Produksi dan Pendapatan}

Perhitungan pendapatan agroindustri kripik ubi selama bulan Desember 2016 tahun disajikan padsa tabel 3 .

Tabel 3.Produksi dan Pendapatan Agroindustri kripik ubi Kayu "SUGENG SNACK" bulan Desember Tahun 2016.

\begin{tabular}{|r|l|r|r|r|r|r|r|}
\hline NO & \multicolumn{1}{|c|}{ Varian rasa } & \multicolumn{1}{c|}{$\begin{array}{l}\text { Jumlah } \\
(\mathrm{Kg})\end{array}$} & $\begin{array}{c}\text { Harga } \\
(\mathrm{Rp} / \mathrm{Kg})\end{array}$ & $\begin{array}{c}\text { Pendapatan } \\
\text { Kotor }(\mathrm{Rp})\end{array}$ & $\begin{array}{c}\text { Total Biaya } \\
(\mathrm{Rp})\end{array}$ & $\begin{array}{c}\text { Total } \\
\text { Pendapatan } \\
\text { Bersih (Rp) }\end{array}$ & $\begin{array}{c}\text { Pendapatan } \\
\text { Bersih/Kg } \\
(\mathrm{Rp} / \mathrm{Kg})\end{array}$ \\
\hline 1 & Kripik Ubi Balado & 2.432 & 22.000 & 53.504 .000 & 40.822 .557 & 12.681 .443 & 5.214 \\
\hline 2 & $\begin{array}{l}\text { Kripik Ubi } \\
\text { Original }\end{array}$ & 1.710 & 22.000 & 37.620 .000 & 26.054 .574 & 11.565 .426 & 6.763 \\
\hline 3 & $\begin{array}{l}\text { Kripik Ubi Cabe } \\
\text { (sanjai) }\end{array}$ & 855 & 33.600 & 28.728 .000 & 23.104 .409 & 5.623 .591 & 6.577 \\
\hline & Total & 4.997 & & 119.852 .000 & 89.981 .540 & 29.870 .460 & \\
\hline
\end{tabular}

Sumber: Olahan Data Primer 2016

Pada tabel 3. dapat dibahas bahwa pendapatan bersih selama bulan Desember sebesar Rp.29.870.460,-. Pendapatan bersih perkilogram kripik yang tonggi adalah kripik ubi original Rp.6.763,-/Kg, berikutnya kripik ubi cabe (sanjai) Rp.6.577,-/Kg, yang paling rendah adalah kripik balado Rp. 5.214,-/Kg.

\section{Analisis Break Even Point (BEP), analisis Volum-Biaya dan Analisis Nilai Tambah}

Pehitungan nilai BEP pada agroindustri kripik ubi milik pak Sugeng disajikan pada tabel 4.

Tabel 4. Nilai Break Even Point Kripik Ubi Kayu "SUGENG SNACK" Berbagai Varian Rasa Agroindusri Pak Sugeng Bulan Desember 2016

\begin{tabular}{|r|l|r|r|r|}
\hline No & \multicolumn{1}{|c|}{ Uraian } & $\begin{array}{c}\text { Kripik } \\
\text { Balado }\end{array}$ & $\begin{array}{c}\text { Kripik } \\
\text { Original }\end{array}$ & $\begin{array}{c}\text { Kripik Cabe } \\
\text { (sanjai) }\end{array}$ \\
\hline 1 & Produksi $(\mathrm{Kg})$ & 2.432 & 1.710 & 855 \\
\hline 2 & Biaya Tetap (Rp) & 809.232 & 606.924 & 337.180 \\
\hline 3 & Biaya Tidak Tetap (Rp) & 40.013 .325 & 25.447 .650 & 22.777 .250 \\
\hline 4 & Total Biaya & 40.822 .557 & 26.054 .574 & 23.114 .430 \\
\hline 4 & Biaya Tidak Tetap/unit $(\mathrm{Rp} / \mathrm{Kg})$ & 16.453 & 14.882 & 26.640 \\
\hline 5 & Harga (Rp/Kg) & 22.000 & 22000 & 33600 \\
\hline 6 & Pendapatan Kotor & 53.504 .000 & 37.620 .000 & 28.728 .000 \\
\hline 7 & Pendapatan Bersih & 12.681 .443 & 11.565 .426 & 5.613 .570 \\
\hline 8 & BEP $(\mathrm{Q})$ & 146 & 85 & 48 \\
\hline 9 & BEP( Rp) & 3.209 .413 & 1.875 .766 & 1.627 .779 \\
\hline
\end{tabular}

Sumber: Olahan Data Primer 2016 
Berdasarkan tabel 4 dapat dibahas bahwa agroindustri kripik ubi milik pak Sugeng berada pencapaian produksinya jauh lebih besar dari pada nilai BEP

untuk semua varian rasa. Ini berarti agroindustri kripik ubi kayu "SUGENG SNACK" layak untuk dilanjutkan. Tingginya selisih anatar nilai BEP dan

Dalam perencanaan bisnis sering dilakukan penetapan laba atau pendapatan bersih. Dalam usaha agroindustri kripik ubi milik pak Sugeng selama bulan Desember tahun 2016 diperoleh pendapatan bersih yang berbeda untuk setiap varian rasa. kripik ubi dengan varian rasa balado pendapatan bersih $\mathrm{Rp}$. pencapaian produksi antara lain disebabkan karena relatif rendahnya biaya tetap dikarenakan dalam proses produksinya masih menggunakan alat-alat yang sederhana. Biaya penyusutan yang relatif besar adalah untuk mobil yang dipergunakan dalam kegiatan pemasaran.

12.681.443,-, Varian rasa Original Rp. 11.565.426,-, varian rasa kripik cabe (sanjai) Rp. 5.613.570,-. Jika pak Sugeng menghendaki laba Rp. 20.000.000 untuk setiap varian rasa, maka dapat dihitung banyaknya kripik ubi yang harus terjual agar target laba dapat tercapai dengan perhitungan sbb:

Tabel 5. Total Penjualan Untuk Mewujudkan Target Laba Agoindustri Kripik Ubi Kayu "SUGENG SNACK" pada Berbagai Varian Rasa Bulan Desember 2016

\begin{tabular}{|c|l|r|r|r|}
\hline No & \multicolumn{1}{|c|}{ Uraian } & \multicolumn{1}{c|}{ Kripik Balado } & \multicolumn{1}{c|}{ Kripik Original } & \multicolumn{1}{c|}{ Kripik Cabe (sanjai) } \\
\hline 1 & Produksi (Kg) & $2.432,00$ & $1.710,00$ & 855,00 \\
\hline 2 & Biaya Tetap (Rp) & $809.232,00$ & $606.924,00$ & $337.180,00$ \\
\hline 3 & Biaya Tidak Tetap (Rp) & $40.013 .325,40$ & $25.447 .650,00$ & $22.777 .250,00$ \\
\hline 4 & Total Biaya & $40.822 .557,40$ & $26.054 .574,00$ & $26.114 .430,00$ \\
\hline 5 & Biaya Tidak Tetap/unit (Rp/Kg) & $16.452,85$ & $14.881,67$ & $33.640,06$ \\
\hline 6 & Harga (Rp/Kg) & $22.000,00$ & $22.000,00$ & $28.728 .000,00$ \\
\hline 7 & Pendapatan Kotor & $53.504 .000,00$ & $37.620 .000,00$ & $5.613 .570,00$ \\
\hline 8 & Pendapatan Bersih & $12.681 .442,60$ & $11.565 .426,00$ & 48,45 \\
\hline 9 & BEP (unit) & 145,88 & 85,26 & $1.627 .779,19$ \\
\hline 10 & BEP( Rp) & $3.209 .413,18$ & $1.875 .766,05$ & $20.000 .000,00$ \\
\hline 11 & Target Laba (Rp) & $20.000 .000,00$ & $20.000 .000,00$ & $2.873,59$ \\
\hline 12 & Tambahan Penjualan (unit) & $3.605,45$ & $2.809,65$ & $2.922,03$ \\
\hline 13 & Total Penjualan (unit) & $3.751,34$ & $2.894,91$ & \\
\hline
\end{tabular}

Sumber: Olahan Data Primer 2016

Total Penjualan untuk mencapai laba Rp.20.000.000,- untuk setiap varian rasa, varian rasa balado adalah $3.751,34 \mathrm{Kg}$, varian rasa original $2.894,91 \mathrm{Kg}$, dan kripik cabe (sanjai) 2.922,03 Kg.

\section{Analisis Nilai Tambah}

Untuk melakukan analisis nilai tambah kripik ubi kayu dari berbagai varian rasa digunakan metode Hayami. Nilai tambah kripik ubi kayu varian rasa balado dengan kerangka analisis nilai tambah metode Hayami disajikan pada tabel 18 sebagai berikut:

Tabel 6. Nilai Tambah Kripik Ubi Kayu "SUGENG SNACK" Brbagai Varian Rasa Bulan Desember 2016

\begin{tabular}{|c|l|r|r|r|}
\hline No & \multicolumn{1}{|c|}{ Variabel } & \multicolumn{1}{c|}{ Balado } & \multicolumn{1}{c|}{ Original } & \multicolumn{1}{c|}{ sanjai } \\
& & & & \\
\hline & Output, Input dan Harga & & & 171 \\
\hline 1 & Output (kg/bulan) & 202,66 & 190 & 450 \\
\hline 2 & Bahan Baku (kg/bulan) & 533,333 & 500 & \\
\hline \hline
\end{tabular}




\begin{tabular}{|c|c|c|c|c|}
\hline 3 & Tenaga kerja (HOK/bulan) & 10,3 & 10 & 9 \\
\hline 4 & Faktor Konversi $(1 / 2)$ & 0,38 & 0,38 & 0,38 \\
\hline 5 & Koefisien tenaga kerja (3/2) & 0,019 & 0,02 & 0,02 \\
\hline 6 & Harga output $(\mathrm{Rp} / \mathrm{kg})$ & 22.000 & 22.000 & 33.600 \\
\hline \multirow[t]{2}{*}{7} & Upah rata-rata tenaga kerja $(\mathrm{Rp} / \mathrm{HOK})$ & 65.760 & 63.500 & 82.500 \\
\hline & $\begin{array}{l}\text { Pendapatan dan Keuntungan (Rp/kg bahan } \\
\text { baku) }\end{array}$ & & & \\
\hline 8 & Harga bahan baku & 1.600 & 1.600 & 1.600 \\
\hline 9 & Sumbangan input lain & 1.760 & 1.095 & 4.062 \\
\hline 10 & Nilai output $(4 \times 6)$ & 8.360 & 8.360 & 12.768 \\
\hline $11 \mathrm{a}$ & Nilai tambah (10-9-8) & 5.000 & 5.665 & 7.106 \\
\hline $\mathrm{b}$ & Rasio nilai tambah $(11 \mathrm{a} / 10) \times 100 \%)$ & $59 \%$ & $67,76 \%$ & $55,65 \%$ \\
\hline $12 \mathrm{a}$ & Imbalan tenaga kerja $(5 \times 7)$ & 1.249 & 1.270 & 1.650 \\
\hline $\mathrm{b}$ & Bagian tenaga kerja (12a/11a) x 100\%) & $24,98 \%$ & $22,42 \%$ & $23,22 \%$ \\
\hline $13 \mathrm{a}$ & Keuntungan $(11 \mathrm{a}-12 \mathrm{a})$ & 3.751 & 4.395 & 5.456 \\
\hline \multirow[t]{2}{*}{$\mathrm{b}$} & Tingkat keuntungan (13a/11a) x $100 \%$ & $75,02 \%$ & $77,58 \%$ & $76,78 \%$ \\
\hline & Balas Jasa Faktor Produksi & & & \\
\hline 14 & Marjin (10-8) & 6.760 & 6.760 & 11.168 \\
\hline $\mathrm{a}$ & Pendapatan tenaga kerja & $18,41 \%$ & $18,78 \%$ & $14,77 \%$ \\
\hline $\mathrm{b}$ & Sumbangan input lain & $26,03 \%$ & $16,19 \%$ & $36,37 \%$ \\
\hline c & Keuntungan perusahaan & $55,48 \%$ & $65,01 \% \%$ & $48,85 \%$ \\
\hline
\end{tabular}

Sumber: Olahan Data Primer 2016 
Nilai tambah dengan metoda Hayami, diperoleh Nilai output Kripik Ubi Kayu Balado sebesar Rp. 8.360,memberikan nilai tambah sebesar Rp.5.000,- atau sebesar 59\%. Usaha keripik balado memperoleh keuntungan sebesar Rp. 3.751 per kg dengan tingkat keuntungan sebesar 75,02\%

Nilai output Kripik Ubi Original sebesar Rp. 8.360,- memberikan nilai tambah sebesar Rp. 5.665,- atau sebesar

\section{KESIMPULAN DAN SARAN}

\section{Kesimpulan}

Berdasarkan analisis data dapat

disimpulkan sebagai berikut:

1. Biaya proses produksi agroindustri kripik ubi kayu "SUGENG SNACK" Bulan Desember 2016 varian rasa balado adalah Rp. 40.822.557,40, varian rasa original $\mathrm{Rp}$. 40.822.557,40 dan kripik cabe (sanjai) Rp. 22.777.250,00. Pendapatan bersih kripik ubi kayu varian rasa balado adalah Rp. 12.681.442,60, atau Rp. $5.214 / \mathrm{Kg}$; varian rasa original $\mathrm{Rp}$. 11.565.426,00 atau Rp. 6.763/Kg ; dan kripik cabe (sanjai) Rp. 5.613.570,00. atau Rp. 6.577,-/Kg

2. Nilai BEP (Q) agroindustri kripik ubi kayu "SUGENG SNACK" Bulan Desember 2016 varian rasa balado adalah $145,88 \mathrm{Kg}$, varian rasa original $85,26 \mathrm{Kg}$ dan kripik cabe (sanjai)

\section{Saran}

1. Mengingat dari hasil analisi kelayakan agroindustri kripik ubi kayu "SUGENG SNACK" usaha ini disarankan untuk dilanjutkan. kripik ubi kayu ketiga varian perlu
67,76\%. Usaha keripik ubi kayu memperoleh keuntungang sebesar Rp. 4.395 per $\mathrm{kg}$ dengan tingkat keuntungan sebesar $77,58 \%$.

Nilai output Kripik Ubi Balado (sanjai) sebesar Rp.12.768,- memberikan nilai tambah sebesar Rp. 7.106,- atau sebesar $55,65 \%$. Usaha keripik sanjai memperoleh keuntungan sebesar Rp. 5.456 per $\mathrm{kg}$ dengan tingkat keuntungan sebesar $76,78 \%$.

48,45Kg. Total Penjualan untuk mencapai laba Rp.20.000.000,- untuk setiap varian rasa, varian rasa balado adalah $3.751,34 \mathrm{Kg}$, varian rasa original $2.894,91 \mathrm{Kg}$, dan kripik cabe (sanjai) $2.922,03 \mathrm{Kg}$.

3. Nilai tambah agroindustri kripik ubi kayu "SUGENG SNACK" Bulan Desember 2016, varian rasa balado adalah nilai output sebesar Rp. 8.360,memberikan nilai tambah sebesar Rp.5.000,- atau sebesar 59\%, varian rasa original nilai output sebesar $\mathrm{Rp}$. 8.360,- memberikan nilai tambah sebesar Rp. 5.665,- atau sebesar 67,76\%., dan kripik cabe (sanjai) nilai output sebesar Rp.12.768,- memberikan nilai tambah sebesar Rp. 7.106,- atau sebesar $55,65 \%$ ditingkatkan produksi dan upaya pemasarannya karena ketiga varian rasa ini memiliki nilai keuntungan hampir sama yaitu varian balado $75,02 \%$, varian original bilai 
keuntungan sebesar 77,58\% dan varian sanjai sebesar $76,78 \%$.

2. Perlu dipertimbangkan untuk dibuat kemasan yang lebih menarik supaya produknya dapat menembus super market.

3. Perlu ada uji coba pengembangan varian rasa yang lain sehingga menarik konsumen.

\section{DAFTAR PUSTAKA}

W. David Downey, Steven P. Erickson ( Terjemahan olh Rochidayat Ganda S.). Manajemen Agribisnis.Erlangga.1992.Jakarta

Hayami Y, Kawagoe T, Morooka Y, Siregar M. 1987. Agricultural Marketing and Processing in Upland Java. A Perspective from a Sunda Village. Bogor: The CPGRT Centre.

Ibrahim Yakob. H.M. Study Kelayakan

Bisnis. PT. Rineka Cipta. 2001 Jakarta.

Sukartawi, 2001. Pengantar Agroindustri.Raja grafindo Persada.2001. Jakarta

Suparmoko. Pengantar Ekonomika Mikro. BPFE.1987. Yogyakarta

Supriyati dan Erma Suryani. Peranan, Peluang dan Kendala Pengembangan Agroindustri Indonesia.

Pse.Litbang.deptan.go.id: $\quad 12-12$ 2010: 17.44

Syarif Hidayat1, Marimin, Ani Suryani, Sukardi, Mohamad Yani. 2012. Modifikasi Metode Hayami Untuk Perhitungan Nilai Tambah Rantai Pasok Agroindustri Kelapa Sawit. Jurnal eknologi Industri Pertanian 22.(1): 22-31 (2012)

Widodo.2003. Peran Agribisnis Usaha Kecil dan Menengah Untuk Memperkokoh Ekonomi Nasional. 